\title{
How to achieve international action on falsified and substandard medicines
}

Substandard and falsified medicines kill patients, yet progress on the twin challenges of safeguarding the quality of genuine medicine and criminalising falsified ones has been held back by controversy over intellectual property rights and confusion over terms. Amir Attaran and colleagues propose a global treaty to overcome the problems

Amir Attaran Canada research chair in law, population health, and global development policy ${ }^{1}$, Donna Barry policy and advocacy director ${ }^{2}$, Shamnad Basheer professor in intellectual property ${ }_{\text {law }}{ }^{3}$, Roger Bate resident scholar ${ }^{4}$, David Benton chief executive officer ${ }^{5}$, James Chauvin president ${ }^{6}$, Laurie Garrett senior fellow for global health ${ }^{7}$, Ilona Kickbusch director, global health programme ${ }^{8}$, Jillian Clare Kohler director global health ${ }^{9}$, Kamal Midha immediate past president ${ }^{10}$, Paul N Newton reader in tropical medicine ${ }^{11}$, Sania Nishtar president ${ }^{12}$, Paul Orhii director-general ${ }^{13}$, Martin McKee professor of European public health ${ }^{14}$

'University of Ottawa, 1 Stewart St, Ottawa, ON, K1N 6N5, Canada ; ${ }^{2}$ Partners in Health, Boston, USA; ${ }^{3}$ National University of Juridical Sciences, Kolkata, India; ${ }^{4}$ American Enterprise Institute, Washington, USA; ${ }^{5}$ International Council of Nurses, Geneva, Switzerland; ${ }^{6}$ World Federation of Public Health Associations, Geneva, Switzerland; ${ }^{7}$ Council on Foreign Relations, New York, USA; ${ }^{8}$ Graduate Institute, Geneva, Switzerland; ${ }^{9}$ University of Toronto, Toronto, Canada; ${ }^{10}$ International Pharmaceutical Federation, The Hague, Netherlands; ${ }^{11}$ University of Oxford, Oxford, UK ; ${ }^{12} \mathrm{Heartfile}$, Islamabad, Pakistan; ${ }^{13}$ National Agency for Food and Drug Administration and Control, Abuja, Nigeria; ${ }^{14}$ London School of Hygiene and Tropical Medicine, London, UK

Every day patients in need of effective treatment receive substandard or fake drugs and other medical products. ${ }^{12}$ At best patients taking these compromised products get no relief from their symptoms; at worst they may die. In poor countries, half of medicines for some deadly diseases are fake and have little or no active ingredient. ${ }^{3}$ In rich countries, medicine safety is better, but substandard and falsified drugs still cause thousands of adverse reactions and some deaths. ${ }^{4-6}$ As the outsourcing and international trading of medicines becomes standard, patients everywhere are vulnerable. $^{45}$

In 2010, after years of debate, WHO's member states established a working group to decide how best to tackle this scandal, but progress remains halting. ${ }^{7}$ The working group (now called the member state mechanism) still cannot agree how to define the various poor quality medicines, much less settle on any concrete actions.

There are several reasons for this inadequate progress, yet all are possible to overcome. In this article we-a diverse group of authors from the health professions, health charities, legal and medical academia, and former or current government officials in health-outline the current challenges and propose possible solutions.

\section{Common interest}

The most fundamental reason for current and past inaction is a failure to recognise shared goals. Although drug companies, non-governmental organisations, and governments all want reliable access to safe and effective medicines and deplore unsafe fake medicines, it is difficult to achieve agreement on action because discussions too often trespass into conflict prone areas such as pharmaceutical pricing or intellectual property.

For agreement to be achieved, care and restraint will be needed to avoid these distracting arguments. One source of disagreement is that anticounterfeiting laws in some countries give prominence to the protection of commercial interests and pay little or no attention to protecting public health interests. ${ }^{8}$ In East Africa, poorly worded reforms to anticounterfeiting laws, supported by some pharmaceutical companies, threatened to impede the availability of generic medicines on which most ordinary Africans depend. ${ }^{9}{ }^{10}$ Likewise in Europe, customs authorities seized legitimate generic AIDS and cancer medicines that were in transit from India to Brazil because they infringed European intellectual property and were ostensibly counterfeit. ${ }^{11}$ Rather than promoting understanding and trust, these decisions generated an understandable activist backlash because they 
endangered affordable access to medicines. ${ }^{8}$ If progress is to be made, not only must such apparently provocative actions be avoided, but the rush to controversy must be tempered by all parties on all sides.

\section{Clearer definitions}

Such clashes are often caused by a second fundamental problem: the absence of a clear, internationally agreed terminology to define different sorts of legitimate or illegitimate medicines (box 1).

Everyone agrees that there are two categories of legitimate medicine on the market: proprietary medicines, which are initially marketed under patent, and generic medicines, which are lawful copies of the proprietary medicines either because in a given country the patents have expired or were never granted or because the manufacturer has a licence to use the patent. Despite price differences, both proprietary and generic medicines are produced according to good manufacturing standards, are properly regulated for quality, and can bear brands or trademarks.

The situation and the terminology are far messier for illegitimate medicines. In the past WHO distinguished between

"substandard" and "counterfeit" medicines, but last year member states chose to lump them together in the new term "substandard/spurious/falsely-labeled/falsified/counterfeit medical products" (SSFFC) ${ }^{14}$ However, placing all illegitimate medicines under the SSFFC umbrella gives the misleading, mistaken impression that they are all deficient in the same way, when actually there are many possible deficiencies, each requiring different solutions. We therefore propose new definitions, which refine the views of WHO member states (fig $1 \Downarrow)^{15}$

An important strength of the definitions that we propose is that they do not draw on any intellectual property questions or use the confusing word counterfeit. According to international intellectual property law, a "counterfeit" medicine is one that infringes a registered trademark by bearing an identical or near identical mark. ${ }^{16}$ Deliberate counterfeiting is a private economic wrong, which can occur separately from or together with the public health wrong of poor medicine quality. Thus it is a mistake (but a common one) to use the adjective "counterfeit" to refer to medicines that endanger public health. Accordingly we avoid the term here.

"Substandard" medicines are those that for unintentional reasons do not meet the legally required quality specifications of a country's regulators (usually a specialised medicine regulatory authority). As noted elsewhere, substandard medicines have various deficiencies and causes-for example, the raw ingredients may be of poor quality, errors may occur in manufacturing, or mishandling may cause the medicine to degrade or expire. ${ }^{8}$ Each of these technical problems requires a different solution.

"Unregistered" medicines are those that do not have the legally required marketing authorisation of the country's regulators to be imported or sold there-for example, internationally diverted or stolen medicines. Unregistered medicines can occur unintentionally, but more often illicit diversion or theft implies criminal intent to circumvent regulatory approval.

With both substandard and unregistered medicines, some aspect of the medicine does not meet the regulator's legal requirements. Generally such products are also "falsely labelled" because they deviate from the regulator's approved packaging (expired medicines, properly labelled with an end date, are the exception).
The final category is "falsified" medicines. Similar to substandard medicines, the falsified medicines are unlawful in violating the regulator's quality specifications-but what truly defines and distinguishes them is criminal intent. Thus it takes more than a negligent breach of the regulator's legal requirements to make a medicine falsified; there must also be a deliberate intent to deceive or wilful blindness. For example, while an expired medicine is merely substandard, if the date is altered to make it appear not expired, that deliberate fraud makes it falsified. Lawyers call this element of criminal intent mens rea (guilty mind), and it signals to the justice system to prosecute and punish instances of falsified medicines as serious crimes, not just regulatory violations or civil negligence claims.

\section{Surveillance and research}

The third problem is that there is little reliable information on the global scale of the falsified medicine problem. ${ }^{1}$ The UN Office of Drugs and Crime implicates China and India as the major exporters of "counterfeit" medicines, some of which are doubtless also falsified, because both governments acknowledge problems enforcing medicine quality laws. ${ }^{17-19}$ Case reports and small scale studies document products containing the wrong ingredients or bogus ingredients such as chalk, with the deception disguised by sophisticated copies of the packaging and holograms, or the cunning use of wrong ingredients that mimic the proper active ingredient in analytical tests. ${ }^{30-22}$ These studies leave no doubt that falsified medicines harm and kill-sometimes hundreds of people at a time (box 2).

But how many incidents of falsified medicine are there, how are they trafficked, and most importantly, how can the public be better protected? More surveillance and research are needed to answer these questions satisfactorily. WHO has estimated that less than $1 \%$ of medicines in developed countries, rising to over $10 \%$ in developing countries may be "counterfeit" (using its overbroad definition of the term).$^{27}$ Although an underestimate, in 2009 the Pharmaceutical Security Institute (an organisation set up by 24 drug companies in the 1990s) detected about 2000 incidents of illegitimate medicines of all kinds-five a day-in 118 countries and affecting 808 products in nearly all therapeutic categories. ${ }^{28}$ In the European Union, medicines are now the leading illegitimate product seized at the border, increasing 700\% from 2010 to 2011 (and the seizures would be even higher, if the EU enforced more than just intellectual property violations). ${ }^{29}$

The pharmaceutical industry, researchers, and governments must better partner in acquiring, analysing and publicising knowledge. The Pharmaceutical Security Institute maintains a large database on various medicine crimes, but the industry keeps nearly all the data secret, lest transparency should undermine law enforcement efforts and deter patients from consuming its products. Unfortunately, the industry's secrecy deprives researchers and governments of data that would help raise public awareness of falsification, catalyse political action, and thus improve patient safety. Some form of cooperation and compromise must be reached, whereby secrecy is protected during police investigations but biomedical and criminological researchers gain access soon after. ${ }^{7}$ Just as clinical trial registries have begun to make the industry's once secret trial data more available, more transparency of the industry's medicine crime data is possible.

\section{Avoid conflating issues}

The fourth problem is the mistaken tendency to conflate quality of medicines with tangential concerns such as intellectual 


\section{Box 1 Some definitions of illegitimate medicines and their problems}

WHO notes that consensus has not been reached on the definitions. ${ }^{12}$ As these examples show, current definitions are often imprecise (not separating unintentional from intentional crimes) or overbroad (conflating public health and intellectual property violations).

1992 WHO definition (no longer used)

"A counterfeit medicine is one which is deliberately and fraudulently mislabeled with respect to identity and/or source. Counterfeiting can apply to both branded and generic products and counterfeit products may include products with the correct ingredients or with the wrong ingredients, without active ingredients, with insufficient active ingredient or with fake packaging."12

This definition of counterfeit is restricted to deliberate fraud. However, it does not separate public health violations (wrong or insufficient ingredients) from intellectual property violations (fake packaging) and considers both wrongful.

\section{Council of Europe's Medicrime Convention}

Article 4(j) reads, "the term 'counterfeit' shall mean a false representation as regards identity and/or source."13

The Council of Europe's definition of counterfeit is not limited to deliberate misrepresentations, so it may also criminalise errors that have occurred unintentionally during manufacturing. ${ }^{1 "}$

\section{India's Drug And Cosmetics Act 1940}

Section 9B reads, "A drug shall be deemed to be spurious: $(a)$ if it is imported under a name which belongs to another drug; or $(b)$ if it is an imitation of, or a substitute for, another drug or resembles another drug in a manner likely to deceive or bears upon it or upon its label or container the name of another drug unless it is plainly and conspicuously marked so as to reveal its true character and its lack of identity with such other drug; or $(c)$ if the label or the container bears the name of an individual or company purporting to be the manufacturer of the drug, which individual or company is fictitious or does not exist; or ( $d$ ) if it has been substituted wholly or in part by another drug or substance; or $(e)$ if it purports to be the product of a manufacturer of whom it is not truly a product."

India's definition of "spurious" drugs does not separate public health violations (subsection d) from intellectual property violations (subsections $a, b$, and e). It also is not limited to deliberate fraud.

\section{Box 2: Examples of dangerously compromised medicines in 2011-12}

\section{Substandard heart medicine}

More than 125 people died in Pakistan of bone marrow suppression after a public cardiology pharmacy provided generic

isosorbide-5-mononitrate tablets adulterated with a toxic overdose of pyrimethamine, an antimalarial drug. The substandard product was the result of a manufacturing error, although police allege that company officials learnt of the error and sold the medicine anyway. ${ }^{23}$ If the allegation proves true, the medicine would be reclassified as falsified.

\section{Falsified antiretrovirals}

In Kenya, Médecins Sans Frontières (MSF) unintentionally provided patients with falsified tablets of zidovudine, lamivudine, and nevirapine that criminals had inserted into its supply chain. ${ }^{24}$ The falsified product mimicked the appearance of a generic antiretroviral, but tablets were "in varying degrees of deterioration, ie moulding, discolouration." ${ }^{25}$ Once the problem was discovered, MSF followed-up about 3000 patients with proper medicines and counselling.

\section{Falsified cancer medicine}

Authorities globally are combating falsified bevacizumab of unknown origin. The falsified product closely matches the appearance of the real medicine, but tests indicate that it contains starch and acetone instead of active ingredient. ${ }^{26}$ The fakes were trafficked on a complex supply chain, through Turkey, Switzerland, and Denmark to US, in part by a Canadian firm and its offshore affiliates. The extent of harm to patients is unknown.

property rights. ${ }^{30}$ The confusion arises because pharmaceutical companies sometimes enforce their intellectual property to force counterfeited copies of their products off the market, some of which may also be falsified. (This is why we recommend reserving the term "counterfeit" for private trademark violations and "falsified" for public health crimes.)

Arguments by some non-governmental organisations that "the high price of pharmaceuticals" causes falsification or that lower prices would "eliminate the incentive for the business" are also based on mistaken conflation. ${ }^{31}{ }^{32}$ Such arguments fail to recognise that any legitimate medicine, regardless of price, can be produced more cheaply and profitably by criminals using fake instead of real ingredients. Thus falsification occurs not just in expensive proprietary medicines but also the cheapest generic medicines, including those on the WHO model list of essential medicines that cost only pennies (for example, ampicillin, chloroquine, or tetracycline).$^{33}{ }^{34}$ Worryingly, medicines on WHO's essential list may be especially attractive to falsify because there is a huge global demand and because most are unpatented, meaning criminals face no risk from angry patent holders suing or demanding prosecution. Even basic generics can be falsified with tragic results-for example falsified paracetamol syrup has killed hundreds (mostly children) in Bangladesh, Haiti, India, and elsewhere. ${ }^{35}$ Like most crime, falsification is opportunistic, occurring where regulatory defences are lowest, not necessarily where profits are highest.

\section{Using international law}

We argue that tackling the challenges of poor quality, unsafe medicines requires a comprehensive global strategy on which all stakeholders agree. Both falsified and substandard medicines endanger public health, but their countermeasures are different. ${ }^{8}$ A new global treaty could tackle them simultaneously and synergistically through legal, technical, and financial measures (fig $2 \Downarrow$ ).

The governance of the global medicine trade currently suffers from a dangerous imbalance: international trade laws force open countries' markets to imported medicines and pharmaceutical ingredients, but no complementary international health laws defend countries from trafficked products of dangerously bad quality. Purely technical initiatives are not sufficient to safeguard quality because they are not legally binding (box 3). A binding international law on drug quality - that is, a treaty-is needed to complement the existing trade treaties and put public health on an equal plane.

Currently, the biggest problem with the governance of falsified medicines is that they are legal in global trade. ${ }^{40}$ Responsible governments can and do prohibit falsified medicines under national law but remain vulnerable to organised criminals doing business in "haven" countries (both rich and poor) where laws or enforcement are lax-30\% of countries have little or no medicine regulation according to WHO. In other contexts global treaties have helped governments strengthen their laws and 


\section{Box 3: Some global initiatives against dangerously compromised medicines}

Pharmacopoeias-WHO publishes the International Pharmacopoeia, comprising technical specifications and testing methods for medicines and their ingredients. ${ }^{36}$ WHO monographs, as well as those of national pharmacopoeias, are often cited in national drug regulation laws as legally binding standards

Police operations - Interpol coordinates national police forces in drug seizure and arrest operations, including Operation Pangea, targeting medicines sold illegally on the internet. ${ }^{37}$ Some credit card companies, internet search companies, and domain registrars are informally supporting these efforts

Regulatory harmonisation-The International Conference on Harmonisation strives to set uniform technical standards for registering and regulating medicines in most developed countries. ${ }^{38}$ Similar efforts are nascent in some developing regions, such as the East African Community's medicines registration harmonisation initiative

Pharmacovigilance-Although WHO has a mandate to advise countries in recording adverse events of medicines and to publish medicine alerts, member states seldom report events to WHO. Data collection at the global level therefore remains sporadic and unreliable ${ }^{1}$ Verifiable serialisation (track and trace)—Various countries mandate that medicine packages bear unique serial numbers that can be electronically verified at point of sale. However, lack of agreement on an internationally accepted technology or data standards risks making country by country compliance hard and costly

Prequalification-Because of the special political will surrounding HIV/AIDS, malaria and tuberculosis, WHO screens manufacturers of medicines for these diseases in a voluntary prequalification scheme. ${ }^{39} \mathrm{WHO}$ reviews drug dossiers, inspects sites, and provides advice and training. Nearly 300 medicines are currently WHO prequalified

cooperate internationally to clamp down on the havens-for example, on human trafficking or money laundering. The lack of a treaty means there is generally no agreement on which medicines are wrongful or criminal; no requirement for police to cooperate across borders in carrying out international investigations; and no requirement for prosecutors to share evidence or to respond to extradition requests to bring perpetrators to justice. ${ }^{40}$ These omissions translate into impunity for medicine criminals.

A successful treaty would deal with both falsified and substandard medicines but treat them differently. Using our definitions, falsified medicines are deliberate, intentional frauds and should be prohibited using criminal measures. In contrast, substandard medicines are unintentional or negligent errors that require regulatory measures to correct. The "positive" regulatory agenda and the "negative" criminal agenda are synergistic, as in other policy contexts (for example, food is regulated for safety, but adulterating food is a crime). Both agendas depend primarily on national medicine regulatory authorities, with ancillary support from customs, police, justice ministries, and frontline healthcare workers. As well as setting norms and expectations for governments, a treaty could raise new money through a dedicated financial mechanism to help needy countries build regulatory capacity for medicines, assuring quality manufacturing and training healthcare workers.

Thus the growing political energy to fight falsified medicines could, if wisely channelled into a treaty that also includes substandard medicines, provide new financing and reinforced capabilities against both dangers.

\section{Action plan towards a global treaty}

The treaty would need to fulfil five functions:

- Define legally the different types of illegitimate medicines, possibly using the terms we propose, so as to avoid confusion and unwelcome over-reaches against legitimate medicines

- Define new public health crimes in international law, such as to manufacture, traffic, or sell falsified medicines

- Mandate intergovernmental cooperation so that countries report, investigate, and prosecute transborder crimes and seize criminals' assets

- Create an ongoing intergovernmental forum to protect the legitimate medicines trade, such as by setting global standards for authenticating medicines with tracking and tracing technologies or by setting standards for medicine sales on the internet

- Include administrative provisions, particularly to give financial and technical assistance to strengthen medicine regulatory authorities in poorer countries.

Other consensus building exercises have identified many of the same elements, ${ }^{41}$ and conveniently, these elements have precedents in other treaties. A 1929 treaty to criminalise counterfeit banknotes internationally provides an obvious analogy for falsified medicine. ${ }^{42}$ This month a new protocol under today's leading public health treaty, the Framework Convention on Tobacco Control (FCTC) will legally mandate global tracking and tracing for tobacco products and internationally criminalise illicit trade-oddly making the law tougher on cigarette falsification than on medicine falsification. The FCTC also shows that treaties can raise new financial resources: nearly $\$ 250 \mathrm{~m}$ ( $£ 155 \mathrm{~m}$; $€ 190 \mathrm{~m})$ is now spent annually on global tobacco control. ${ }^{43}$ More dramatic examples exist in various environmental treaties, through which the Global Environment Facility has raised over \$50bn in foreign aid directly and in co-funding. ${ }^{44}$ These and other successful precedents are adaptable for medicines.

What are the reasonable next steps? WHO's member states should ask WHO staff to embark on a similar process to that which created the FCTC, which began with a technical working group and led to formal negotiations among diplomats in an international negotiating body. That project should have the limits we describe here, such as excluding work related to intellectual property, and should involve other international organisations when matters exceed WHO's public health mandate (for example, the UN Office on Drugs and Crime is better suited to law enforcement than WHO). To build the political case and will for action, the pharmaceutical industry and Pharmaceutical Security Institute should cooperate with independent researchers on studies that generate knowledge and raise awareness about the scale and provenance of illegitimate medicines. This starting framework, we believe, avoids unnecessary controversy and can better enable governments, companies, advocates, and the health professions to protect the public's health.

Contributors and sources: The authors collaborated on this article both as representatives of the global health professions, and individual experts in drug regulation, pharmacy, medicine, health diplomacy, law, public policy, and so forth. This article arose out of discussions among the authors over a course of nearly two years. 
Competing interests: All authors have completed the ICJME unified declaration form at www.icmje.org/coi_disclosure.pdf (available on request from the corresponding author) and declare that $\mathrm{AA}$ received funding from Canada's Social Sciences and Humanities Research Council and that PNN received funding from the Wellcome Trust. WHO has paid consultancy and travel expenses to IK; the authors have no other relationships or activities that could appear to have influenced the submitted work.

Provenance and peer review: Not commissioned; externally peer reviewed.

1 Cockburn R, Newton PN, Agyarko EK, Akunyili D, White NJ. The global threat of counterfeit drugs: why industry and governments must communicate the dangers. PLOS Med 2005;2:e100.

2 Newton PN, McGready R, Fernandez F, Green MD, Sunjio M, Bruneton C, et al. Manslaughter by fake artesunate in Asia-will Africa be next? PLoS Med 2006;3:e197. 3 Newton PN, Green MD, Fernández FM, Day NP, White NJ. Counterfeit anti-infective drugs. Lancet Infect Dis 2006;6:602-13.

4 Okie S. Multinational medicines-ensuring drug quality in an era of global manufacturing. N Engl J Med 2009;361:737-40.

5 Pew Charitable Trusts. After heparin: protecting consumers from the risks of substandard and counterfeit drugs. 2011. www.pewtrusts.org/uploadedFiles/wwwpewtrustsorg/Reports/ Health/Pew_Heparin_Final_HR.pdf.

6 Nordt SP, Minns A, Tomaszewski C, Cantrell FL, Clark RF. Retrospective review of digoxin exposures to a poison control system following recall of Digitek® tablets. Am J Cardiovasc Drugs 2010;10:261-3.

7 Fighting fake drugs: the role of WHO and pharma. Lancet 2011;377:1626.

8 Oxfam. Eye on the ball: medicine regulation—not IP enforcement—can best deliver quality medicines. 2011. www.oxfam.org/sites/www.oxfam.org/files/eye-on-the-ball-medicineregulation-020211-en.pdf.

9 Mullard A. EU implicated in controversial counterfeiting bill. Lancet 2010;375:1335

10 Von Braun J, Munyi P. New enforcement mechanisms challenge the legality of generics in the name of public health: the emergence of anti-counterfeiting legislation in East Africa. Afr J Int Comp Law 2010;18:238.

11 Bate R, Attaran A. A counterfeit drug treaty: great idea, wrong implementation. Lance 2010;376:1446-8.

12 World Health Organization. Counterfeit medical products: Report by the secretariat. 2010. http://apps.who.int/gb/ebwha/pdf files/WHA63/A63 23-en.pdf.

13 Council of Europe. Convention on the counterfeiting of medical products and similar crimes involving threats to public health. 2011. http://conventions.coe.int/Treaty/EN/Treaties/ $\mathrm{Html} / 211 . \mathrm{htm}$

14 WHO. WHO's role in the prevention and control of medical products of compromised quality, safety and efficacy such as

substandard/spurious/falsely-labelled/falsified/counterfeit medical products. 2011. http:// apps.who.int/gb/ssffc/pdf files/A SSFFC WG2 3-en.pdf.

15 WHO. Report of the working group of member states on

substandard/spurious/falsely-labelled/falsified/counterfeit medical products. 2011. http:// apps.who.int/gb/ssffc/pdf_files/A_SSFFC_WG5-en.pdf.

16 World Trade Organization. Trade-related aspects of intellectual property rights. WTO, 1994

17 UN Office on Drugs and Crime. The globalization of crime: a transnational organized crime threat assessment. 2010. www.unodc.org/documents/data-and-analysis/tocta/ TOCTA_Report_2010_low_res.pdf.

18 India Parliamentary Standing Committee on Health and Family Welfare. Fifty-ninth report on the functioning of the central drugs standard control organisation. New Delhi, 2012.

19 China State Council. The national "twelfth five-year plan" for drug safety. Beijing, 2012.

20 Bate R, Coticelli P, Tren R, Attaran A. Antimalarial drug quality in the most severely malarious parts of Africa-a six country study. PLoS One 2008;3:e2132.
21 Ahmad K. Antidepressants are sold as antiretrovirals in DR Congo. Lancet2004;363:713.

22 Beni S, Limtiaco JFK, Larive CK. Analysis and characterization of heparin impurities. Anal Bioanal Chem 2011;399:527-39

23 Choudary A. Police body recommends action against 17 people. Dawn (Pakistan). 2012. www.dawn.com/2012/02/14/police-body-recommends-action-against-17-people.html.

24 HIV/AIDS in Kenya: majority of patients with suspect Zidolam- $\mathrm{N}$ receive follow-up consultations. 2011. www.msf.ca/themes/news-reader/2011/11/hivaids-in-kenya-majorityof-patients-with-suspect-zidolam-n-receive-follow-up-consultations.

25 WHO. Falsified lamivudine, zidovudine and nevirapine tablets (Zidolam-N) in Kenya. 2011. http://apps.who.int/prequal/info_press/documents/Falsified_ZidolamN_23September2011. pdf.

26 Weaver C, Whalen J. How fake cancer drugs entered US. Wall Street Journal 2012 Jul 20. http://online.wsj.com/article/SB10001424052702303879604577410430607090226. html?mod=WSJ hps MIDDLENexttoWhatsNewsForth.

27 WHO IMPACT. Counterfeit medicines: an update on estimates. 2006. www.who.int medicines/services/counterfeit/impact/TheNewEstimatesCounterfeit.pdf.

28 Kubic TT. Law enforcement and industry: key partners for safe medicines. J Biolaw Business 2010;13:38-41.

29 European Commission. Report on EU customs enforcement of intellectual property rights: results at the EU border, 2011. http://ec.europa.eu/taxation_customs/resources/documents/ customs/customs_controls/counterfeit_piracy/statistics/2012_ipr_statistics_en.pdf.

30 Berkeley declaration on intellectual property enforcement and access to medicines. 2010. www.law.berkeley.edu/files/Berkeley_Declaration.pdf.

31 People's Health Movement. Items for consideration during the 64th WHA. 2011. www. phmovement.org/sites/www.phmovement.org/files/PHMLetter2WHADelegates110516. pdf.

32 Third World Network. WHO's "counterfeit" programme: legitimises IP enforcement agenda, undermines public health. 2010. www.twnside.org.sg/title2/briefing_papers/nontwn/Briefing paper.on.WHO.Counterfeits.pdf.

33 Newton PN, White NJ, Rozendaal JA, Green MD. Murder by fake drugs. BMJ 2002;324:800-1.

34 Erhun WO, Babalola OO, Erhun MO. Drug regulation and control in Nigeria: the challenge of counterfeit drugs. World Health Pop 2001;4:23-34.

35 Schep LJ, Slaughter RJ, Temple WA, Beasley DM. Diethylene glycol poisoning. Clin Toxicol (Phila) 2009;47:525-35.

36 WHO. The international pharmacopoeia. www.who.int/medicines/publications pharmacopoeia/overview/en/index.html.

37 Interpol. Pharmaceutical crime. 2012. www.interpol.int/content/download/3902/37957/ version/17/file/Factsheets EN jun2012 DCO04.pdf.

38 Molzon JA, Giaquinto A, Lindstrom L, Tominaga T, Ward M, Doerr P, et al. The value and benefits of the international conference on harmonisation to drug regulatory authorities: advancing harmonization for better public health. Clin Pharmacol Ther 2011;89:503-12.

39 WHO. WHO prequalification of medicines programme: facts and figures for 2011. http:// apps.who.int/prequal/info general/documents/annual_reports/2011_PQP-Summary.pdf.

40 Attaran $A, B a t e ~ R$, Kendall $M$. Why and how to make an international crime of medicine counterfeiting. J Int Crim Justice 2011;9:325-54.

41 Garrett L. Ensuring the safety and integrity of the world's drug, vaccine, and medicines supply. www.cfr.org/global-health/ensuring-safety-integrity-worlds-drug-vaccine-medicinessupply/p28256.

42 Fitz-Maurice E. Convention for the suppression of counterfeiting currency. Am J Int Law 1932;26:533.

43 Callard C. Follow the money: how the billions of dollars that flow from smokers in poor nations to companies in rich nations greatly exceed funding for global tobacco control and what might be done about it. Tobacco Contr 2010;19:285-90.

44 Global Environment Facility. What is the GEF? www.thegef.org/gef/whatisgef.

Accepted: 26 October 2012

Cite this as: BMJ 2012;345:e7381

(c) BMJ Publishing Group Ltd 2012 


\section{Figures}

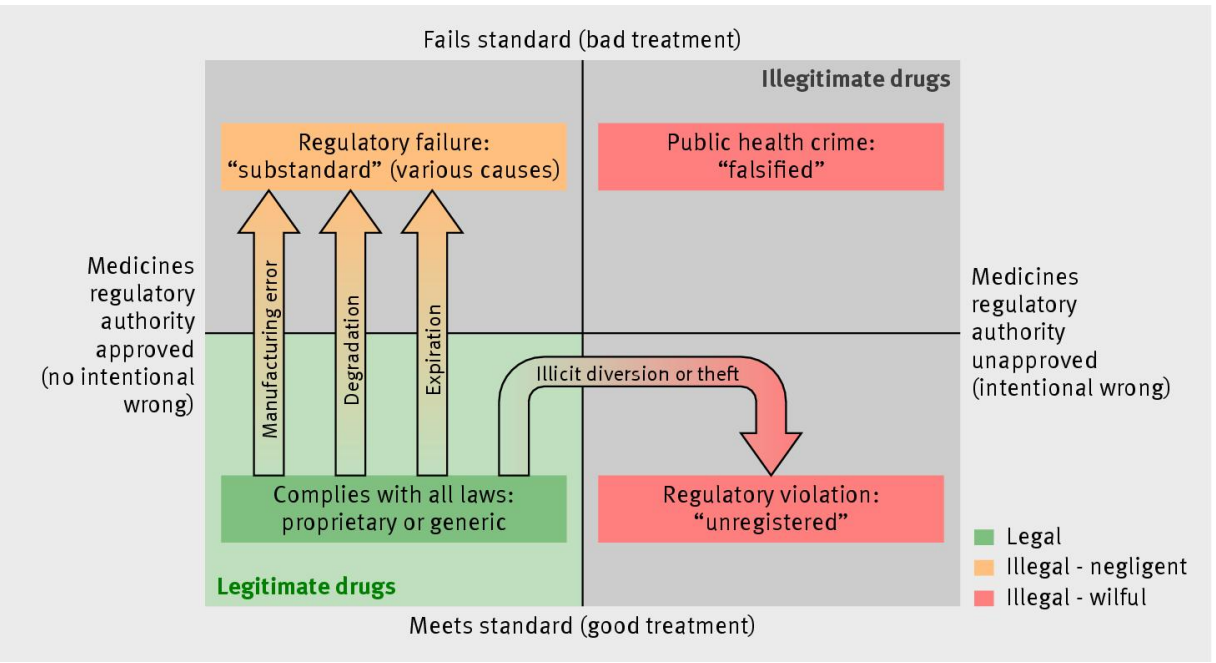

Fig 1 Categories of legitimate and illegitimate medicine

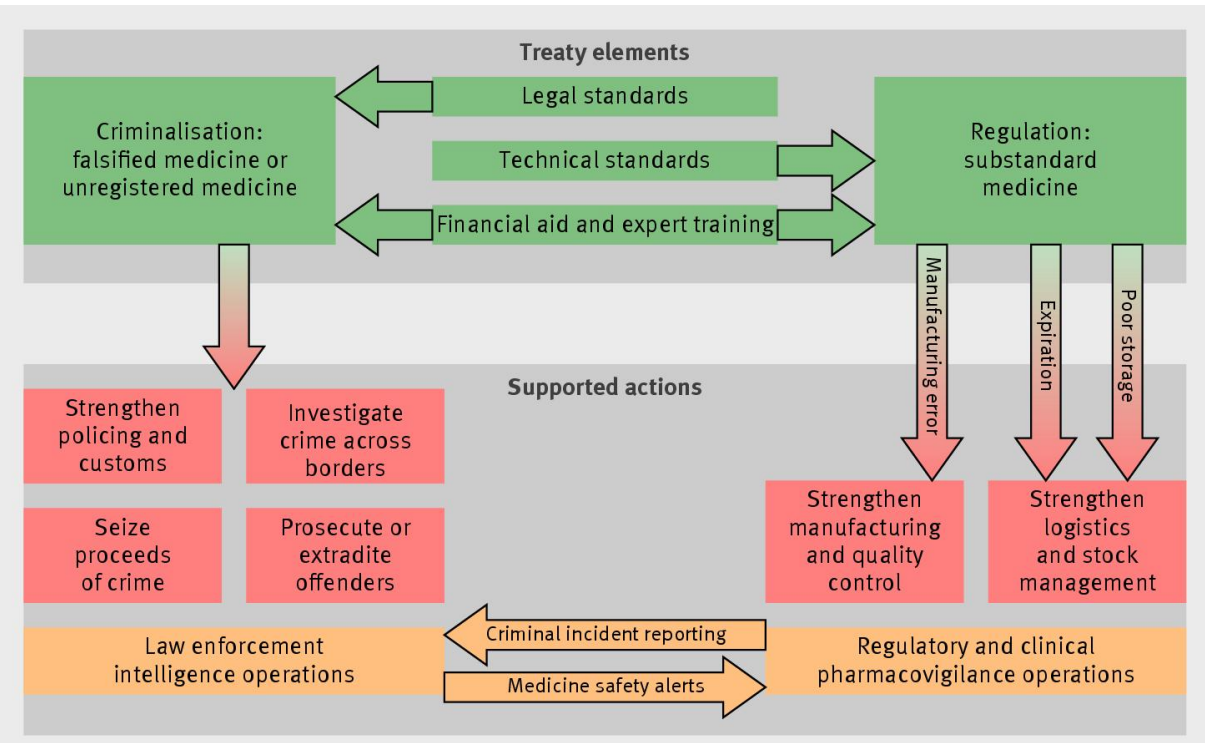

Fig 2 Elements of a treaty to improve the safety of medicines. The figure shows the linkages between treaty elements (green), directly supported actions (red), and supporting information exchanges (orange) 